This is a pre-proof version of Goodings, L. \& Tucker, I. M. 'Social media and the co-production of bodies online: Bergson, Serres and Facebook Timeline, Media, Culture \& Society, in press

\title{
Social media and the co-production of bodies online: Bergson, Serres and Facebook Timeline
}

\begin{abstract}
Social media's networked form of communication provides people with bodies that are combinations of embodied and technologically-mediated action. This creates multiple forms of visibility within the infospheres (Terranova, 2004) of social media, which require simultaneous production of bodies in and through offline and online spaces. Bergson's non-dualistic model of bodies as images addresses the challenges of experiencing 'bodies online'; understood as expressions that blur the subject-object and representation-being dualisms. This paper explores how socially mediated bodies are disposed for action in ways that involve negotiating communication through the mediated noise (Serres) of social media, along with managing bodies that are faced with the spatialisation of time through new features such as Facebook Timeline.
\end{abstract}

\section{Keywords}

Bergson, bodies, mediation, Serres, social network sites, Facebook Timeline

\section{Introduction}

Matter, in our view, is an aggregate of 'images'. And by 'image' we mean a certain existence which is more than that which the idealist calls a representation, but less than that which the realist calls a thing an existence placed halfway between the 'thing' and the 'representation'. (Bergson, 1988: 9)

The above quote, from the opening page of Henri Bergson's (1988) Matter and Memory, captures the importance he places on the role of the 'image' in human psychology. For Bergson images are what bodies perceive, and yet they cannot be reduced to a dualistic understanding in which the objects of the world are said to exist only as representations in our minds, which we have direct psychological access to. Clearly seeking to overcome the 'frankly dualistic' thinking of the early 20th Century, Bergson's ideas about images and their relation to bodies have been recruited in recent times in new media theory as ways to potentially avoid another form of dualism, namely the online-offline (real-virtual) distinction that blights much Internet-related theory (Hansen, 2004). We will follow this line of thinking in exploring the implications for socially mediated bodies, of living lives that are simultaneously embodied and informational, e.g. Facebook profiles. Characterising bodies as distinctly online and offline, as if each has an autonomous mode of operation appears unhelpful, so we will develop a position that frames them as produced relationally with constant connections rather than separate forms. Furthermore, a temporal rather than spatial understanding of the past online will be articulated, in relation to the issues at work in living with Facebook's Timeline feature.

For Bergson, our bodies are centres of action, produced through processes of selective perception, in which attention is manifest as action directed towards and by engagement with multiple 'images'. The image, for Bergson, is a way out of the dualistic thinking of 'materialism-idealism' brought about when using the traditional psychological language of representation. In Bergson's model, the body is just one image amongst a world of images; a 'centre of indetermination' that, through action, interacts with other 
images which can increase and decrease its capacity to act. Bergson states '[M]y body, an object destined to move other objects, is, then, a centre of action; it cannot give birth to a representation' (1988: 20 original emphasis). Bodies are also centres of movement, not static spatialised entities. Bergson thinks of the world as a universe of images, and as such any 'thing' that is perceived, be it a body, a gust of wind, or an emotional reaction to bad news, is an image, akin to a sliver of the world cut away. Images are movement, they are not entities that are separate from the force of movement.

This model fits into Bergson's wider philosophy of duration, in which experience is seen as operating against the backdrop of an ever growing past; '[D]uration is the continuous progress of the past which gnaws into the future and which swells as it advances' (Bergson, 1960: 5). Bergson does not conceptualise the world as a series of objects that the mind (body) forms a representation of, but rather sees bodies as affective centres of action; filters that select from the universe of images those that are relevant to it (Hansen, 2004). The body is central to Bergson's philosophy, as it is a special kind of image. It is the only one that is known from within; '[Y]et there is one of them which is distinct from all the others, in that I do not know it only from without by perceptions, but from within by affections; it is my body' (1988: 17). It is this knowing from within that sets bodies apart from other images.

Social media present a challenge to the Bergsonian understanding of the body, as they provide the opportunity for us to present and produce our bodies in technologically-mediated spaces in which they become images in a traditional sense as well as being technologically-extended images known from within. It is this extended knowing that is of interest in this paper. We do not know online bodies from within, but as a projected body, performed in the technological rather than purely biological realm. The questions then become 'how people come to produce and know themselves in and through social media?' 'What kinds of challenges and dilemmas are faced when living through social media?' Bergson's psychological model of bodies as images is challenged when producing bodies online, as we are faced with seeing our bodies as others do. And yet, it is our body produced online. So, although it is visible to us as it is others, we still have a relation to it, which is distinct to our relation to other bodies. This links to Deleuze's Bergsonian-influenced idea of the body as manifest as 'the interior as a selected exterior and the exterior a projected interior' (1988: 125). Online bodies can be framed as this 'projected interior'. Presenting online bodies as some kind of representation or virtual self, would be to laden ourselves with all the reductionist and dualistic baggage that Bergson sought to avoid. Instead, we follow an ontological line of multiplicity and fluidity, in which bodies are not stable entities with predefined patterns of being, but are shifting and multiple, formed in and through relations with other images, both human and nonhuman. In social media, bodies are produced in the information-technological space of sites that provide multiple opportunities for people to present their bodies as centres of action, or 'movement images' (Deleuze, 1986).

\section{Socially mediated bodies}

How then to understand the body in these technologically mediated spaces? Donna Haraway argues that meanings are encoded in technology in different ways and that all machines have a 'material-semiotic' essence that is reflected in their form. In The Cyborg Manifesto (1985) Haraway moves beyond the traditional notion of human and machine and explores how the computer is an object that does not stand alone from our everyday activities as 'they are everywhere and they are invisible' (1985: 193). Haraway treats the 'cyborg' body as one that blends the actions of human and non-human actors. This work emphasises the changing boundaries of the body and the machine and shows how we (as cyborgs) are 
always embodied. The first publication of the Cyborg Manifesto in the mid-1980s had a profound effect on feminism and cyberculture more broadly. The embodied cyborg was a way of recasting the relationship with technology and made a bold statement about offline social and political inequalities, and how people are under pressure to accept their cyborg bodies of race, class, gender and sexuality.

In a more recent attempt to understand the digital body, Danah boyd (2006) describes how the users of social network sites 'write themselves into being' through the use of textual statements on a profile page. Boyd explains how users create a 'digital body' by populating the different elements of a profile page and the digital body provides a way of transgressing the problems associated with trying to maintain a connection through a computer e.g. a lack of a shared physical location or the ability to connect with a visible audience (boyd and Ellison, 2008). However, this approach focuses on the textual construction of the body while it is clear that many social network sites continue to involve new ways of organising the visual aspects of the profile page, which must also impact on how people can build and sustain the digital body. There is also a concern that focusing on the body as something that has to be linguistically produced in Facebook pages is likely to further valorise the dualistic models of real/virtual or being/representation.

Our view is that all communication is mediated in some way and that this mediation involves a range of specific cultural and historical practices that are unique to the specific site of mediation. Socially mediated bodies emphasise the ways that technologies like Facebook and other social media sites have the capacity to shape people, places and things through the joint enactment of humans and technologies. This definition is intended to recognise that the body is an assemblage of relations; a body that is enacted from moment to moment and where the attachment or detachment to locally available technologies helps different parts of the body to have absence or presence (Munro, 1999). As stated above, Bergson highlighted how the body is known 'from within' as a special kind of knowing, and it is also crucial to remember that it is through our bodies that we become sensitive to the world and what it is made of (Latour, 1993; Mol, 2002). Our bodies online are increasingly becoming the product of a distinct set of body-information assemblages where the activities that take place in social media are routinely mined by different organisations and replayed to the user through some aspect of social connectedness (Tucker \& Goodings, in press). Ultimately, the body is disposed for action in a number of ways in social media and there is an entire surface of activity that takes place outside of an individual's conscious awareness, in what Thrift (2004) refers to as the 'technological unconscious'. Recent research argues that the body is the main site through which understanding of the world is formed, but that the body is not just an object of knowledge and as a result it can be both knowing and unknowing (Latimer and Schillmeier, 2009). Therefore, our online bodies are co-produced by a number of actors that are present at the moment of making oneself present through social media.

The use of a Bergsonian model of the body, in which it is just one of a number of images, directs this research away from a dualistic rendering of body-representation or real-virtual. In the analysis that follows we explore the ways people experience the socially-mediated production of their bodies. Focus is on how the characteristics of online communication come to be known, along with the ways social media make past activity available for communication in the present.

\section{Method}

This data for this research comprised of 8 focus groups that explored the way people use social media. Twenty five participants were recruited from a university in London. Each of the focus groups lasted 
approximately 1 hour and the participants were asked questions such as 'how do you connect with people through social media?' and 'what is the relationship between people and technology in the age of social media?' The semi-structured interview schedule was intended to allow the participants to lead the direction of the focus group and give the group an opportunity to collectively discuss the matters arising.

The analysis borrowed techniques from discourse analysis (DA) to examine the ways that people speak about the body and social media. DA is broadly informed by the principles of discursive psychology (Edwards and Potter, 1992) where there is a focus on the social function of language and how certain forms of language lead to particular forms of action. This approach is interested in the fluid and varied orientation towards a particular action in language and illustrates the performative qualities of speech. DA is a reliable method for analysis what people are doing with their talk and matches the ongoing need to blur the distinction between reality and representation. Standard ethical procedures were put into place to ensure the confidentiality of the participants and as a result all of the names that feature in the following analysis are pseudonyms. DA is of particular use for identifying the tensions or contradictions that exist in the communication. In DA you assume that any variation might be significant, that it has something to do with the way that the interaction occurs, or with the way that the text produces its meaning. Discourse analytic research is often represented in themes in order to group together any prevalent issues in the data.

\section{Analysis}

The following themes were identified in the analysis of the focus group data: i) the experience of multiple bodies connecting online ii) a resistance to spatially inscribing the body. The themes both illustrate a dilemma that relates to the production of online bodies in a space where human and computers are jointly involved in the process.

\section{The experience of multiple bodies connecting online}

\section{Extract 1. FG4}

Sarah: Well I I've sort of noticed almost that there's a sense of branding yourself on social media so you you have an idea of what you want to construct or how you want to present or project yourself to the outside world so you you you construct you pull certain features certain aspects of your life that you'd like people to be aware of and then the challenges of how you communicate that through something like Facebook and I suppose what I was talking about was the the collisions that I've had as I've tried to present myself as a 40 something woman when I've been confronted with myself as a 20 year old or myself as a 30 year old or...

The 'collisions' that Sarah speaks of show the difficulties of encountering her body not as a singular form, but as a set of multiple bodies that are brought together by the way that Facebook connect people across different spaces and times. What this means is that when online bodies are fed back to us through Facebook there can be a sequence of unanticipated connections. To Facebook users, like Sarah, it also presents a moment where the computer mediation is revealed, a process that requires managing the 
coming together of bodies from different 'space-times'. This is a distinct problem in social media, as in offline social situations it is typically accepted that our different bodies or selves are unlikely to collide. This links nicely to how Foucault describes the self in his later work:

It is not a substance. It is a form, and this form is not primarily or always identical to itself. You do not have the same sort of relationship to yourself when you constitute yourself as a political subject who goes to vote or speaks at a meeting and when you are seeking to fulfil your desires in a sexual relationship. Undoubtedly there are relationships and interferences between these different forms of subject; but we are not dealing with the same type of subject. In each case, one plays, one establishes a different relationship to oneself. (Foucault, 2000: 290-1)

What Foucault is showing here is the feeling that is associated with different embodied experiences and how when we occupy different social bodies there is a distinct set of subjectivities that do not normally cross. Foucault exemplifies this point when discussing how different forms of one's body should not normally meet, e.g. when one is fulfilling their sexual desires compared to when they go out to vote. They are distinct relational forms and therefore do not occupy the same space. Facebook and other social media present a dilemma to users as they bring together a variety of positions that would not normally interact in offline environments. For Sarah this was the experience of managing connections with people through Facebook who knew her at different times in her life. Being contacted by someone you knew when aged twenty, at the age of forty, involves being presented with one's past in a very specific way, namely one's twenty year old body and all the connections it had. Trying to re-live this twenty year-old body as a forty year old is a challenge. One can think about the interactional problems that can arise when 'bumping into' someone from the past. Contact could have originally ended because of a falling out, a change of location, or just part of the ebb and flow of social relationships. Whichever, meeting them in the present involves the potential imposition of elements of the relationship in the past to the interaction in the present. This is a very direct form of the past attempting to shape the present. This is not something that features commonly offline, and yet social media provide countless opportunities of this kind.

In Extract 1, Sarah also comments on the need to 'brand yourself' in social media and this notion of branding captures the way Sarah has to 'pull certain features' of her life together so that they will come to represent her body in Facebook. Here the body is likened to having a set of brand-like qualities where there is a need to manage the public image of the body, and where this image of the body will be reproduced in a number of ways across Facebook. However, this form of branding leads to a set of difficulties at an interactional level e.g. that you have to continually manage the brand across a number of different social relationships. This shows that the difficulty with branding the body in a particular way is the ongoing need to consider the brand in an ever-changing flow of network connections. Most noticeably, this problem is a concern for Facebook users who need to confront the competing information that is produced by other users such as when they post information which does not confirm the wider performance of the brand. This information has the potential to disrupt the production of a desired body image. The technology provides a number of unwanted bodily assemblages that present the opportunity to contradict the prescribed profile identity or brand. Therefore each user needs to be continually connected to all online activity and be prepared to interject any anti-brand associations. This shows how the affective composition of bodies in online spaces is embedded in a set of collective labour practices that enhance and restrict the production of a brand 'me'. Consider the further ways that the participants describe their problems with managing the multiplicity of bodies online: 
Extract 2. FG5

Dave: like I modified my identity once cos this was before I realised if you liked something then it pops up on your wall or or certain things do and there was one particular like little sign or something and like a photo with some writing over it that said er that moment er I think it was something like liking being "so drunk you've lost your way home" or something or oh it was its something some reference to being drunk anyway and I clicked like cos I thought oh it was quite funny but then then it started appearing on my wall all the time and I thought actually I want to unsubscribe to this cos I don't want people looking at it and thinking that yeah I'm just pro getting drunk all the time that's not the kind of person I want to be seen to be

\section{Extract 3. FG5}

Rachel: I remember I didn't realise at first or I don't know if they changed it so that it was more easy for people to see the conversation and actually read it before it was like it showed up on the wall but now they do it as you can actually see the conversation and you're not in it which I think is kind of bad because like that makes people pry or know about a conversation that doesn't involve them erm so in a way I would be careful more careful what I write and that's why you'd use like Facebook chat or direct messages or even just face to face to talk to them so in a way that does change the way I speak its not as personal.

These examples further show the difficulties associated with producing bodies online in social media. Dave did not anticipate the simple act of 'liking' a particular post could have the repercussions of others being tempted to see his identity as an extension of the blog post ('cos I don't want people looking at it and thinking that yeah I'm just pro getting drunk'). This form of technologically mediated publicness can also explain why people can produce themselves as a multiplicity of online bodies, but where users can still feel a sense of wholeness across their different online bodies. This may account for why Dave felt the need to delete the potentially inflammatory comment from his profile and he describes the problem as a somewhat unconscious moment ('there was one particular like little sign or something and like a photo') and the link between the technological intertwining of this moment with the online body as a whole ('but then then it started appearing on my wall all the time').

Understanding of the unwanted 'extras' of communicating on Facebook can be developed with Michel Serres' (1982) idea of parasitism, which points to the importance of mediation in human communication. The parasite is the necessary mediator that makes possible forms of communication between two previously unrelated systems. Applied to human relations the notion of parasitism tells us something of the non-dualistic nature of communication; how a reliance on distinct notions of individualsociety and/or agency-structure would render simplistic relations that are embedded in topological patterns, in which some kind of 'third element' is necessary so as to make other agents discernible: 
Given two stations and a channel. They exchange messages. However, a third is necessary for the channel. The relation is there in third position, and it is there in first position. Exchanges are possible only if a relation is instituted. (1982: 80)

In any given exchange the presence of what Serres refers to as a 'third' is essential; a channel cannot be formed without it. The third element is the intermediary, the mediating space that makes exchanges intelligible. The technological performance of this mediated connection involves what Serres refers to as 'noise'. In any given communication an 'extra' layer (noise) is created, through the act of mediation, against which the desired act of connection takes place. Communication is not pure, and as such, contributes something to an exchange in the form of 'noise'. One can think of the static of a radio signal, crackling on a telephone line, or a stutter in a voice. Serres argues that communication requires an ongoing struggle to intervene and mediate noise. So noise does not simply refer to a technical term of communication engineering, but refers to an additional element that is produced through the mediated act of communicating. In the case of social media this involves the mediated technological space of connecting online.

Dave and Rachel's communication in Facebook is focused on conveying certain messages from their sender perspective, e.g. about a night out. Yet, Facebook introduces intermediary actions in terms of the visibility of the communication to those who will receive the message. The technology itself works in such a way as to create certain forms of noise. For Rachel, this is the visibility of her online interactions, awareness of which shapes the form such interactions take. Her online body is faced with the challenge of managing desire to interact online and benefit from its associated social value, whilst also attempting to limit the noise, which requires a close attention to the bodily-technological amalgamations that reduce future opportunities for communication. Serres was also keen to argue that communication cannot dispense with noise as it is could not exist without it. For Serres, communication relies on noise, it cannot function without the mediating space it creates, yet is also necessary to try to limit the noise to make the communication 'successful' in the eyes of the sender. Rachel's online body is able to come into being through the movement away from the noise, while simultaneously reiterating the need for such a process to communicate difference and conflict. Therefore, noise is a necessary and indispensable element of the communication that has a high amount of communicative power, but also jointly has the power to consume the communication entirely.

Moreover, communication often relies on trying to ignore or reduce the 'noise' introduced by the intermediary. For instance, the chastising of a child by a parent for an action that is funny but not appropriate can involve the parent trying to lessen their humorous tone whilst the child's understanding is very much shaped by the 'noise' of the underlying humour. The sender (parent) focuses on the 'signal' of the exchange (chastising), whereas the receiver (child) is presented with a 'signal-noise' couplet (chastising-humour). So, for Serres, it is not possible to rid communication of noise. Rachel attempts to shift to an alternative 'noise pattern' through moving on to the 'chat' and 'direct message' modes to reduce the visibility of her interactions. Doing so may reduce the noise, and for Rachel, may even appear to erase it completely. Yet, even the apparent 'clean' modes of chat and direct messaging will involve an additional layer of informational activity, e.g. its recording by security services that target perceived 'private' spaces and the universal data harvesting that social media sites engage in through extracting value from the informational activity taking place therein.

Facebook is also a host. It welcomes people to its technological environment and then extracts something from the exchanges taking place through it. With Rachel we saw examples of what online 
bodies are required to do to attempt to reduce the noise of exchanges online, namely shifting through different modes of exchange, as if trying to elude the gaze of the host. In Serrian logic a parasite extracts from a host without offering anything in exchange, which he develops through his story of the tax farmer and the country and city rats that are involved in a complex system of extraction and exchange. The fable involves the tax farmer parasitizing the local farmers by extracting tax from their labour; the city rat parasitizing the tax farmer through eating the food debris falling from the tax farmer's feast, and the country rat, invited by the city rat, parasitizing the city rat through extracting some of its leftovers. A succession of exchanges takes place, ending only through the interruption of the farmer returning when he hears the scurrying and gnawing of the rats in the dining room. The interruption acts as noise, and also as message, the feast has ended, the rats scurry away through fear of being caught.

The fable of the rats and tax farmer tells us something about the Serrian model of host and parasite. Roles can change and be multiple. The city rat was both parasite and host. With social media a similar framing can occur, with it acting in many ways as a host but also parasite. Facebook users act as parasites through their use of the site for communicative ends for "free" and yet they also come to be hosts of information that can then be parasitized by other users and Facebook itself. Such relations are multiple and subject to differentiation depending on the communicative mode taken. This links with the earlier analysis in Extract 1 that showed the need to build a 'brand' identity in Facebook and illustrated how the multiplicity of a Facebook identity required a level of immaterial labour.

\section{Resistance to spatially inscribing the body}

In this section participants discussed the implications of Facebook's Timeline feature, which allows users to plot any moment in their lifetime in a visual timeline. Other members of their friendship network can then see these moments in a continuous sequence of events, starting with the most recent. Posts and events are displayed down the centre of the page and Facebook users are able to hide certain aspects of the timeline as well as add different events by manually inserting them into the timeline. In March 2012, Facebook pages were forced to convert into Timeline mode as opposed to opting to have the Timeline feature added to their profile. Facebook users were routinely given two weeks to amend their timeline before it went 'live' to their friendship group. As a result, most users end up with a truncated timeline that includes a large amount of information on their more recent experiences (from the launch of Facebook onwards) and very little at the earlier stages of the timeline (before they joined Facebook). Each timeline appears unique as users are able to upload videos, photos, text and other miscellaneous graphics, and as such the ability to bring the digital body into being requires the mobilisation of a number of visual and textual resources that also calls forward a coming together of time and space.

\section{Extract 4. FG1}

Maria: especially now with the Timeline you have to be aware of everything that you posted on someone else's wall or on your own wall everybody can see it now even if its like 5 years ago I can if I said something bad about a person and then befriended him now he can see it that I wrote something about him so I think it's important that everybody knows you have to be really really careful about what you're writing and even if it's a private message that person you're writing it to might just say "hey come look what this person said about you" 


\section{Extract 5. FG6}

George: and its easy to like its easy to like make fake profiles as well so you know you put your whole life up and someone could take everything that you've got make a new profile do something completely with your details and everything and then you know you're screwed really so

Charlotte: Or people have like a profile for their parents and family and one for for their friends which is kind of weird

Diane: Yeah

Charlotte: plus you know you can go back in your Timeline for so long George: yeah Charlotte: so you actually look what somebody did like 35 years ago and I think that's a bit scary George: its like developing along and so I think I think before it was kind of I dunno I would prefer to say that before it was more safer than now I think now it's open like way too much going way back to a thing that maybe you don't want to see them or you don't to be shown to other people so...

In the above extracts participants report a general distaste for the prospect of representing their lives in the Timeline format, for example, Charlotte states 'you actually look what somebody did like 35 years ago and I think that's a bit scary'. Here, looking at what somebody 'did' seems to be semantically different to who they are or what they are like (terms which users of social network sites regularly encounter).

Knowing what somebody 'did' seems to be interactionally problematic as it mediates a fixed sense of the body, which follows along in a linear fashion and where all moments can be understood in terms of a succession of fixed points in the past. This function fails to grasp the ability for the past to be created anew in our daily attempts at reordering the past. Consider how Brian Massumi (2002: 200) describes the need for understanding the body as a non-euclidean, topological space:

The problem is that if the body were all and only in the present, it would be all and only what it is. Nothing is all and only what it is. A body present is in a dissolve: out of what it is just ceasing to be, into what it will have already become by the time it registers that something has happened. The present smudges the past and the future.

Massumi illustrates how the present is not cut off from the past and the future. In fact, he argues that the 'future-past' is continually moving through the present in a way that past experiences and future potentials are interwoven. Massumi marks the importance of the 'potential' status of the body in the present, arguing that it is impossible to uncouple the body from the possibility of future changes. The Facebook Timeline fundamentally misinterprets this feature of the relationship between the body and change. For example, Extract 4 shows how there seems to be an aversion to viewing the past as a complete unit and Maria comments on how she has to be really 'careful' to monitor her actions over time. This could be seen as resistance to the spatial conceptualisation of the relationship between the body and time in Facebook. One explanation is that it is the 'fixing' of the past that causes a problem for this participant as it fails to account for future variability and difference which are erased through the use of 
the Timeline. It is as if the totality of one's past (and to an extent one's future) is simplified and restricted by its actualisation through the Timeline.

The experience of Timeline relates to Bergson's concept of 'bodies as images' which continually move, as opposed to being defined as stable spatial entities. For Bergson, the world consists of nothing other than images. Here the Facebook Timeline acts as a kind of force that spatialises past social media activity and goes against the virtual aspect of memory for Bergson, in which the past is not contained but endures, taking a temporal not spatial form. Consider the way that Bergson describes how the past 'gnaws into the future':

Duration is the continuous progress of the past which gnaws into the future and which swells as it advances. And as the past grows without ceasing, so also there is no limit to its preservation.

Memory, as we have tried to prove, is not a faculty for putting away recollections in a drawer, or of inscribing them in a register. There is no register, no drawer; there is not even, properly speaking, a faculty, for a faculty works intermittently, when it will or when it can, whilst the piling up of the past upon the past goes on without relaxation. In reality the past is preserved by itself, automatically. In its entirety, probably, it follows us at every instant; all that we have felt, thought and willed from earliest infancy is there, leaning over the present which is about to join it, pressing against the portals of consciousness that would fain leave it outside. (Bergson, 1960: 5)

From this perspective we see how the past is not located in any form of 'faculty' and how remembering does not require any cognitive device as 'past is preserved by itself, automatically'. This presented our participants with something of a problem. As Bergson noted, thinking the past as stored somewhere is problematic, favouring a temporal understanding of continuous movement instead. Yet, for Facebook users this is exactly what they are now facing, their past social media activity stored and recorded chronologically, with connections to friends and family. In Extract 4 Maria experiences a problem of having her life laid out through Timeline, which is then visible to others and where her spatialised past takes a quasi-public form through being visible to Facebook 'friends'. Not only this, but it encroaches on the future in terms of being potentially visible to unspecified 'future friends', who may find themselves represented in Maria's Timeline. This realisation requires Maria to manage the present in light of what may have occurred in the past (e.g. "what if I said something bad about someone"), and moreover, to see the present as the future-past, through being wary about how it will become one's visible past in Timeline. What the participants are faced with is a kind of 'prosthetic digital memory' (Lash \& Lury, 2007). Participants' negative responses to this event demonstrate what can be at stake if a form of spatialised memory is artificially imposed on one's past. Visual records of the past have long existed in the form of photographs and home video recordings, yet they do not tend to be visible to the numbers of people one may be connected with through Facebook. Moreover, social media records significantly more of one's everyday lives than photographic records that often involve 'special events', such as family holidays and birthdays.

Furthermore, the spatialisation of one's past acts to stabilise it, to actualise aspects of it that have taken place through social media. Of course, that will only be a selection of everyday life (although as social media usage increases so does the percentage captured). The totality of the past will not be captured on a Timeline, but a mediated version, that then comes to act as determinant of past activity, as it feeds 
into present and future. One of the features of this is that people do not have to undertake some of the stabilising work themselves, which often takes the form of a 'spatialisation of experience' (Middleton \& Brown, 2005), in which events of the past are made visible so as to effect connections with others. This requires spatialisation, with stories of past events often taking a locational form (e.g. described in terms of space and place). The use of spatial characterisations allows for the apparent stabilisation of the past in the present. This fits into the Kantian view of time as a spatial homogenous form, which Bergson argued against through the concept of duration. For social media users this is often a process that occurs verbally during everyday interactions. The use of visual aids can feature, such as photographs, and the internet has provided new kinds of opportunity for the spatialisation of experience. Prior to widespread social media (e.g. Facebook, Twitter) such activity often only occurred through personal desire to experiment with what the Internet can offer in terms of social relationships, e.g. 'family websites' (Middleton \& Brown, 2005).

These features are integral in practices of remembering (Middleton \& Brown, 2005), which are undertaken against the backdrop of the past in entirety. Facebook's Timeline, on the other hand, is a selected actualisation, a succession of linear 'snapshots', which become the past from which present and future action unravel. People are faced with a spatialised form of digital memory that is out of line with offline experience. So, whilst in the first instance Kant's homogenising of time, which Bergson found so problematic, appears to fit our participants' experiences, it is actually how the online spatialisation of the past goes against the heterogeneity of offline duration that is important. Instead of providing new possibilities for experience, Facebook Timeline actually restricts experience and activity through its artificial and reductive form of digital memory. The reality of having one's past laid out and made visible to others is felt as artificial, an impediment to everyday living. Moreover, as Middleton \& Brown (2005) note, the past can be a burden, and in the case of the Timeline a very visible one against which one's socially mediated present has to be organised. Foucault (1970) regularly spoke of the power of the narrative to consume the body and how the narrative reduces the body to docility and submissiveness. This means that the Facebook Timeline forces the users to relinquish the ability to re-create the body in new ways and locked into a particular bodily narrative. Therefore, we might account for the dislike of the Facebook Timeline due to the production of the body as in the past - a space with limited opportunities for the production of new subjectivities, which results in the need to establish alternative lines of flight. For example, each of the participants speaks of the Timeline in terms of it being "automatic". Furthermore, inscribing time with a spatial dimension fails to comprehend the way the body captures and makes time relevant. This means that users are destined to feel out of place in Facebook due to the way that the Timeline presents the body in a way that would always be out of line with our offline bodies.

\section{Managing the production of socially mediated bodies}

Understanding the experience of 'being online' is not something easily done through dualistic models of real-virtual or being-representation. In this paper we have sought to show that 'being online' requires certain re-calibrations of bodies as they enter new forms of connectivity. The Bergsonian model of bodies as images directed us toward the idea of bodies as always-already moving and relational, produced as shifting images cut away from the 'universe of images'. A dualistic rendering of body-representation (online) is avoided with the notion of image. Two other things were at stake for our participants' experiences of social media. Firstly, operating and communicating in mediated spaces in which the possibilities for activity to be parasitised are multiple. Serres' concepts of parasite and noise were found 
to be useful for framing the issues at work in managing relationships in and through social media. The potential for high visibility of exchanges presented one participant, Sarah, with a something of a dilemma; the difficulty to attain the perceived benefits of using social media without contributing to the parasitic nature of social media sites. This dilemma can be further conceptualised by considering Bergson's concept of duration and a temporal understanding of memory, which has proved very useful in the field of critical memory studies (Reavey \& Brown, 2006; Brown, Middleton \& Lightfoot, 2001), in examining the difficulties associated with Facebook's new Timeline feature. It was discussed as being problematic due to the compulsion it presents for having one's past technologically spatialised. The problem is that memory is not stored, and as such, Facebook's Timeline presented participants with an artificial experience of having one's past laid out spatially, their past ordered as a series of linear segments. This chronological ordering means people's pasts in Timeline are visible and connected to others', which challenges the Bergsonian model of memory being total, existing and ever growing. Practices of remembering often involve spatialisation, but this is not through a process of cognitive retrieval. Memory, for Bergson, is about movement, a processual activity that is incessant and indivisible. The idea that movement can be segmented comes from a desire to position movement in space. The laying out of one's past activity in Timeline was reported by participants as problemmatic, due to it meaning that 'being online' involves operating against a backdrop of past activity laid out for all 'friends' to see. Furthermore, the parasitic acting of social media results in the extraction of information from people's online activity, which can then feedback into future action through, for example, online targeted advertising.

The relating of a Serrian model of communication with a Bergsonian understanding of memory provided a useful theoretical resource for analysing the challenges faced with co-producing one's online body. Both are oriented towards a processual understanding of experience formed as and through movement, rather than as forms of stable elements, which become subject to movement. Deleuze captures this in stating " $[\mathrm{T}]$ here is no moving body [mobile] which is distinct from the received movement. Every thing, that is to say every image, is indistinguishable from its actions and reactions: this is universal variation." (1986: 58). Serres and Bergson share this position regarding the primacy of movement, and develop their analysis of communication and memory respectively upon an underlying philosophy of movement. Our analysis of participants' experiences of social media presents the movement of bodies online as the key challenge, in respect of communication and spatialisation of the past. Participants face particular configurations of moving bodies online that are different to how they experience them in offline environments. The spatialisation of the past through Timeline presented the additional challenge of managing a moving body against a backdrop of a selected past, which requires users to create their past, and which subsequently acts as the backdrop for the production of the present. Timeline does not allow for the past to exist in entirety (as per Bergson) and consequently places potential restrictions on the present and future movements of online bodies.

\section{References}

Bergson H (1960) Creative Evolution. London: Macmillan \& Co. Bergson H (1988) Matter and memory. New York: Zone Books. 
Brown SD, Middleton D and Lightfoot G (2001) Performing the past in electronic archives: Interdependencies in the discursive and non-discursive ordering of institutional rememberings. Culture \& Psychology 7(2): 123-144.

Boyd D (2006) Friends, friendsters, and MySpace top 8: writing community into being on social network sites. First Monday 11(12): 4 December.

Boyd D and Ellison NB (2008) Social network sites: definition, history, and scholarship. Journal of Computer-Mediated Communication 13(1): 210-230.

Deleuze G (1986) Cinema. Minneapolis: University of Minnesota Press.

Deleuze G (1988) Spinoza: Practical philosophy (trans R. Hurley). San Francisco: City Light Books. Edwards D and Potter J (1992). Discursive Psychology. London: Sage Publications.

Foucault M (2000) Ethics: Essential works of Foucault 1954-1984 (vol. 1).Harmondsworth Press. Grosz (1999) The Nick of Time: Politics, Evolution, and The Untimely. London: Duke University Press.

Hansen MBN (2004) New Philosophy for New Media. Cambridge, Massachusetts: MIT Press. Haraway DJ (1985) A cyborg manifesto: Science, technology and socialist-feminism in the late Twentieth Century. In: DJ Haraway Simians, Cyborgs and Women: The Reinvention of Nature. New York: Routledge, pp. 149-181.

Lash S and Lury C (2007) Global culture industry: the mediation of things. London: Polity Press. Latimer L and Schillmeier M (eds) (2009) Un/Knowing Bodies. Oxford: Blackwell Publishing. Latour B (1993) We Have Never Been Modern. New York, London: Harvester Wheatsheaf. Massumi B (2002) Parables For The Virtual : Movement, Affect, Sensation. Durham ～N.C.: Duke University Press.

Middleton D and Brown SD (2005) The Social Psychology of Experience: Studies In Remembering and Forgetting. London: Sage.

Munro R (2002) The cultural performance of control. Organisational Studies 20(4): 619- 639.

Mol A (2002) The Body Multiple: Ontology In Medical Practice. London: Duke University Press. Reavey P and Brown SD (2006) Transforming past agency and action in the present-time, social remembering and child sexual abuse. Theory \& Psychology 16(2): 179-202.

Serres M (1982) The Parasite. Baltimore, United States: Johns Hopkins University Press. Terranova T (2004) Network Culture: Politics for The Information Age. London: Pluto Press. Thrift N (2004) Remembering the technological unconscious by foregrounding knowledges of position. Environment and Planning D: Society and Space, 22(1): 175-190.

Tucker, IM, Goodings, L. Mediation and digital intensities: Topology, psychology and social media. Social Science Information, in press. 